\title{
Astragalus-Saffron-Rhubarb Mixture Delays the Progress of Diabetic Nephropathy in db/db Mice
}

\author{
Xiao-Chun Zhou \\ Yao-Jun Liang \\ Long Qin \\ Guo-Hua Wei \\ Jian-Qin Wang
}

Department of Nephrology, Lanzhou University Second Hospital, Lanzhou, 730030, People's Republic of China

Correspondence: Jian-Qin Wang Department of Nephrology, Lanzhou University Second Hospital, No. 82 of Cuiying Men, Chengguan District, Lanzhou, 730030, People's Republic of China

Tel +8613919038I89

Email wangqj26@outlook.com
Objective: This study aimed to investigate the protective effect of astragalus-saffronrhubarb mixture (Bao'shen recipe, BSR) on diabetic nephropathy (DN) in $\mathrm{db} / \mathrm{db}$ mice and preliminarily explore the possible underlying mechanism.

Methods: A total of 1258 -week-old male $\mathrm{db} / \mathrm{db}$ mice with DN were randomly divided into five groups: model group, irbesartan group and high-, medium- and low doses of BSR group, while $25 \mathrm{male} \mathrm{db} / \mathrm{m}$ mice were used as a blank control. At 8, 12, 16, 20, and 24 weeks of feeding, the animals were sacrificed and blood as well as urine samples were collected for blood glucose, urea nitrogen, creatinine and urinary albumin excretion rate (UAER) measurement via blood glucose meter or corresponding detection kits, respectively. The renal tissues of each mouse underwent hematoxylin and eosin (H\&E), Masson, periodic acid Schiff (PAS) staining. Renal homogenate was used to detect IL-6, TNF- $\alpha$, TNF-1R and TNF-2R by enzyme-linked immunosorbent assay. Additionally, the data obtained was statistically analyzed via one-way analysis of variance.

Results: BSR could effectively reduce the body weight, blood glucose, UAER, blood urea nitrogen and creatinine levels, relieve the proliferation of mesangial tissue, and lower the levels of IL-6, TNF- $\alpha$, TNF-1R, and TNF-2R in renal tissue of $\mathrm{db} / \mathrm{db}$ mice with DN. Of note, the high-dose BSR treatment group has advantages over irbesartan treatment group in improving above-mentioned aspects.

Conclusion: BSR could effectively delay the progress of $\mathrm{DN}$, partly related to its antiinflammation effect.

Keywords: diabetic nephropathy, treatment, inflammatory factors, traditional Chinese medicine

\section{Introduction}

Diabetic nephropathy (DN) is the most common and serious chronic complication of diabetes. In developed countries, DN has become the main cause of renal replacement therapy in patients with end-stage renal failure $(\mathrm{ESRF}) .{ }^{1}$ It is estimated that diabetes will become a major disease in developing countries in the next 20 years. About $25-40 \%$ of patients with type 2 diabetes mellitus (T2DM) have renal damage and chronic kidney disease. ${ }^{2,3} \mathrm{DN}$ has multiple pathophysiologic mechanisms involving microvascular, macrovascular changes, the disorder of glucose and lipid metabolism, oxidative stress, inflammation, fibrosis, coagulation, and other factors that play important roles in the progress of $\mathrm{DN}^{4-8}$ Even so, the precise mechanisms in DN are not fully understood. When targeting the pathogenesis of DN, comprehensive management causes the blood glucose, blood lipid, blood pressure, and other indicators to reach the standards, those means of treatment 
can only delay the pathological progression of diabetes mellitus, but it fails to reduce the incidence of ESRD in patients with $\mathrm{DN} .{ }^{4}$ Therefore, finding new treatment measures is the key to the prevention and treatment of DN.

Traditional Chinese Medicine (TCM) plays an important role in the prevention and treatment of chronic kidney disease and T2DM in China, which have been demonstrated by multiple pharmacological and clinical studies. ${ }^{9-12}$ Previous reports showed that Astragalus, saffron crocus and Rhubarb were drugs commonly used for diabetes mellitus and chronic kidney disease, ${ }^{13-15}$ suggesting the possibly protective effects of the above three drugs on DN by mixing them in appropriate proportions. However, the three drugs mentioned above were currently administered mainly as a form of single drug, and little information about mixing them into the Chinese herbal compound for the treatment of DN. Against this backdrop, we previously prepared AstragalusSaffron-Rhubarb Mixture, named Bao'shen recipe (BSR), by combining the afore-mentioned drugs in appropriate proportion and used for patients with chronic renal failure. Additionally, we found that BSR could prevent progress of DN by decreasing the expressions of CTGF and increasing the expressions of MMP-9 in rats with DN. ${ }^{16}$

Based on this, the aim of this study was further to investigate the protective effect of BSR on the kidneys of $\mathrm{db} / \mathrm{db} \mathrm{DN}$ mice and its effects on kidney tissue's inflammatory cytokines associated with the progression of $\mathrm{DN}$, including interleukin-6 (IL-6), tumor necrosis factor- $\alpha$ (TNF- $\alpha$ ), tumor necrosis factor $\alpha$ receptor-1 (TNF-1R), and tumor necrosis factor- $\alpha$ receptor 2 (TNF-2R).

\section{Materials and Methods}

\section{Drug Preparation}

Astragalus, Rhubarb and Saffron were purchased from Lanzhou Huanghe Pharmaceutical Co., Ltd., and the composition of BSR were as follows: Astragalus 60g, Rhubarb $12 \mathrm{~g}$, and Saffron $6 \mathrm{~g}$. The above-mentioned three drugs were soaked in pure water for $30 \mathrm{~min}$ and boiled over high heat until boiling, followed by simmering for 30 minutes. After filtering through four layers of gauze, the BSR was concentrated at a dose of $2.235 \mathrm{~g} / \mathrm{mL}$ and placed in a refrigerator at $-20^{\circ} \mathrm{C}$ for further use.

\section{Animal Feeding, Grouping, and Medication}

Animal maintenance and experimental procedures were carried out in accordance with the US National Institutes of Health guidelines for use of experimental animals and approved by the Animal Care Committee of the Second Hospital of Lanzhou University (Lanzhou, China). One hundred and twenty-five male $\mathrm{db} / \mathrm{db}$ diabetic mice in C57BL/6 background and their nondiabetic littermate control $\mathrm{db} / \mathrm{m}$ mice $(\mathrm{n}=25)$ were obtained from Nanjing Model Animal Research Institute. Mice were housed in a room at a constant temperature of $22 \pm 2{ }^{\circ} \mathrm{C}$ with 12 -h light/dark cycles.

These 6-week-old male $\mathrm{db} / \mathrm{db}$ mice and $\mathrm{db} / \mathrm{m}$ mice were firstly reared adaptively for two weeks, following by randomly divided into five groups of 25 mice per group: control group (distilled water, $\mathrm{db} / \mathrm{m}$ ), model group (distilled water, $\mathrm{db} / \mathrm{db}-\mathrm{m}$ ), positive group (irbesartan, $0.05 \mathrm{mg} / \mathrm{kg}, \mathrm{db} / \mathrm{db}-\mathrm{me})$, high $(3.3525 \mathrm{~g} / \mathrm{kg}$ of crude drug, $\mathrm{db} / \mathrm{db}-\mathrm{hd})$, medium $(2.235 \mathrm{~g} / \mathrm{kg}$ of crude drug, db/db-md) and low $(1.1175 \mathrm{~g} / \mathrm{kg}$ of crude drug, db/db-ld) doses of BSR groups.

\section{Measurement of Body Weight and Fasting Blood Glucose (FBG) Levels}

Body weight and FBG levels obtained by blood glucose meters (Sinocare Inc., China) were measured at 0, 4, 8, 12, and 24 weeks.

\section{Measurement of Biochemical Parameters}

Five mice from each group were killed at the same point by exsanguination under anesthesia before blood samples were collected, followed by centrifuging blood at $3000 \mathrm{rpm}$ for $10 \mathrm{~min}$ at $4^{\circ} \mathrm{C}$ to obtain serum. Urea nitrogen and creatinine were detected using urea nitrogen test kits and creatinine test kits (Nanjing Jiancheng Bioengineering Research Institute, China), respectively. Microalbuminuria was detected using mouse urine microalbuminuria detection kits (Shanghai Enzyme-linked Biotechnology Co., Ltd., China).

\section{Measurement of Inflammatory Cytokines in Renal Tissue Homogenate by Enzyme-Linked Immunosorbent Assay (ELISA)}

Renal tissue was weighed, added with $10 \mathrm{~mL}$ of tissue lysate (the ratio of the radio-immunoprecipitation assay [RIPA]: phenylmethylsulfonyl fluoride [PMSF] was 100:1), and ground at $4^{\circ} \mathrm{C}$ for 30 minutes by electronic tissue homogenizer (Shanghai Jingxin Industrial Development Co., Ltd., China). The tissue homogenate 
was obtained by centrifuging the suspension at $12,000 \mathrm{rpm}$ for ten minutes (Beckman Coulter, USA, model: Allegra $\mathrm{X}-30 \mathrm{R}$ ), followed by detecting the levels of IL-6, TNF- $\alpha$, TNF-1R, and TNF-2R by corresponding ELISA Kit [Mouse IL-6 (ab100713), mouse TNF- $\alpha$ ELISA Kit (ab208348), mouse sTNF-1R ELISA kit (TNFRSF1A, ab202408), mouse sTNF-2R ELISA kit (TNFRSF1b, ab202412), Abcam, UK], respectively. All procedures were performed strictly according to the instructions.

\section{Histopathological Evaluation}

Renal tissue was harvested and fixed in 4\% phosphatebuffered paraformaldehyde. After being embedded in paraffin, $3 \mu \mathrm{m}$ thick sections of renal tissue were prepared and deparaffinized in xylene as well as rehydrated in graded ethanol. Then, haematoxylin and eosin (H\&E), PAS and Masson's trichrome stained samples were separately used for histopathological examination.

\section{Statistical Methods}

Data were statistically analyzed using statistical software SPSS25.0. Data with a normal distribution and variance homogeneity were expressed as mean \pm standard deviation ( $x \pm \mathrm{SD}$ ), compared within one group using one-way analysis of variance, and compared between two groups using $t$-tests. $\mathrm{P}<0.05$ was considered statistically significant.

\section{Results}

\section{Tolerance of $\mathrm{db} / \mathrm{db}$ Mice to BSR}

$\mathrm{The} \mathrm{db} / \mathrm{db}$ mice were treated with irbesartan or BSR starting at the 8th week of modeling. No mice developed infections or bites resulting in death during the treatment period, indicating that the mice were well tolerated to BSR.

\section{Effects of BSR on Body Weight, Blood Glucose, and UAER in $\mathrm{db} / \mathrm{db}$ Mice Change of Body Weight}

The body weight of the mice in the blank control $(\mathrm{db} / \mathrm{m})$ group did not change significantly $(\mathrm{P}>0.05)$ in the feeding process. In sharp contrast, the body weight of the mice in the model group was much higher than that of the control group at 8th, 12th, 16th, 20th, and 32nd weeks of feeding ( $\mathrm{P}<0.01$ for all). No significant difference in body weight could be found between the $\mathrm{db} / \mathrm{db}$-me group and the $\mathrm{db} / \mathrm{db}-\mathrm{m}$ group $(\mathrm{P}>0.05)$. Of note, mouse treated with high- and medium doses of BSR performed a lower body weight as compared with mouse in $\mathrm{db} / \mathrm{db}-\mathrm{m}$ group ( $\mathrm{P}<0.05$ for both) at the same time point $(\mathrm{P}<0.01$ for

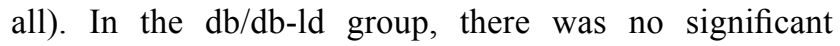
change in body mass before and after medication, and the body mass was the same as that in the $\mathrm{db} / \mathrm{db}$-me group at the same time point ( $\mathrm{P}>0.05$ for all, Figure 1$)$. The results revealed that medium and high doses of BSR could reduce the body weight of mice, and the body weight did not significantly change in the positive control group.

\section{Change of Blood Glucose in db/db Mice}

The blood glucose level of mice in the $\mathrm{db} / \mathrm{db}$-m group was significantly increased as compared with the almost stable blood glucose $(P>0.05)$ level of the mice in the $\mathrm{db} / \mathrm{m}$ group during the experiment, which showed statistical difference at the 8 th, 12th, 16th, 20th, and 32nd week of feeding $(\mathrm{P}<0.01$ for all). Intervention with high- and medium doses of BSR could improve the elevated blood glucose levels of mice in $\mathrm{db} / \mathrm{db}-\mathrm{m}$ group $(\mathrm{P}<0.05$ for both), and the blood glucose levels were lower in these three groups than that of in $\mathrm{db} / \mathrm{db}$-me group at the same time point $(\mathrm{P}<0.01$ for all). In the $\mathrm{db} / \mathrm{db}$-ld group, no significant change could be found in blood glucose levels before and after medication, and the blood glucose levels were not statistically significant as compared with the $\mathrm{db} /$ $\mathrm{db}$-me group at the same time point $(\mathrm{P}>0.05$ for all, Figure 2). Additionally, there was no significant difference in blood glucose levels between the $\mathrm{db} / \mathrm{db}$-me group and the $\mathrm{db} / \mathrm{db}-\mathrm{m}$ group $(\mathrm{P}>0.05)$. The results revealed that medium and high doses of BSR have the ability to reduce the blood glucose level of mice.

\section{Change of UAER in $\mathrm{db} / \mathrm{db}$ Mice}

Similar to the tendency towards blood glucose of mice, the UAER of the mice in the $\mathrm{db} / \mathrm{m}$ group also did not change significantly $(\mathrm{P}>0.05)$ in the feeding process. In sharp contrast, the UAER of the mice in the $\mathrm{db} / \mathrm{db}-\mathrm{m}$ group showed significant elevation $(\mathrm{P}<0.01)$ at 12 weeks of feeding as compared with the $\mathrm{db} / \mathrm{m}$ group. What is of interest was that UAER of the mouse in $\mathrm{db} / \mathrm{db}$-me group and three doses of BSR group were remarkably decreased at $4,8,12$, and 24 weeks of medication $(\mathrm{P}<0.01)$. The UAER in the db-hd group was significantly lower than that of in the $d b / d b$-me group $(P<0.01)$. There was no significant difference in UAER between the $\mathrm{db} / \mathrm{db}$-md group and the $\mathrm{db} / \mathrm{db}$-me group $(\mathrm{P}>0.05$, Figure 3$)$. 


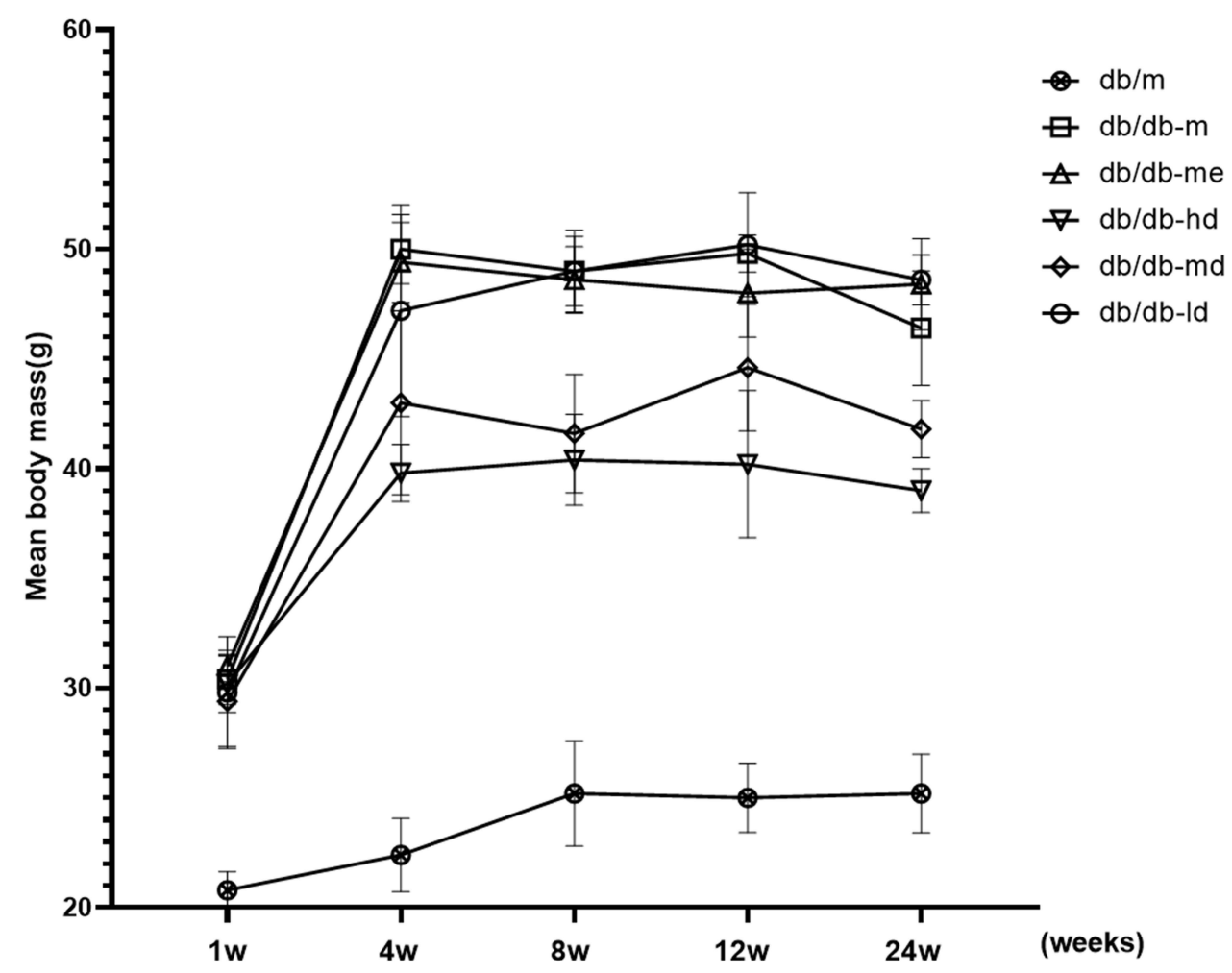

Figure I Effects of BSR on body weight of db/db DN mice. Animals were assigned into six group $(n=25)$ : control group $(d b / m)$, model group (db/db-m), positive group (db/ $\mathrm{db}-\mathrm{me})$ and BSR at high- (db/db-hd), medium- (db/db-md) and low (db/db-ld) doses group. The data are shown as the mean \pm SD.

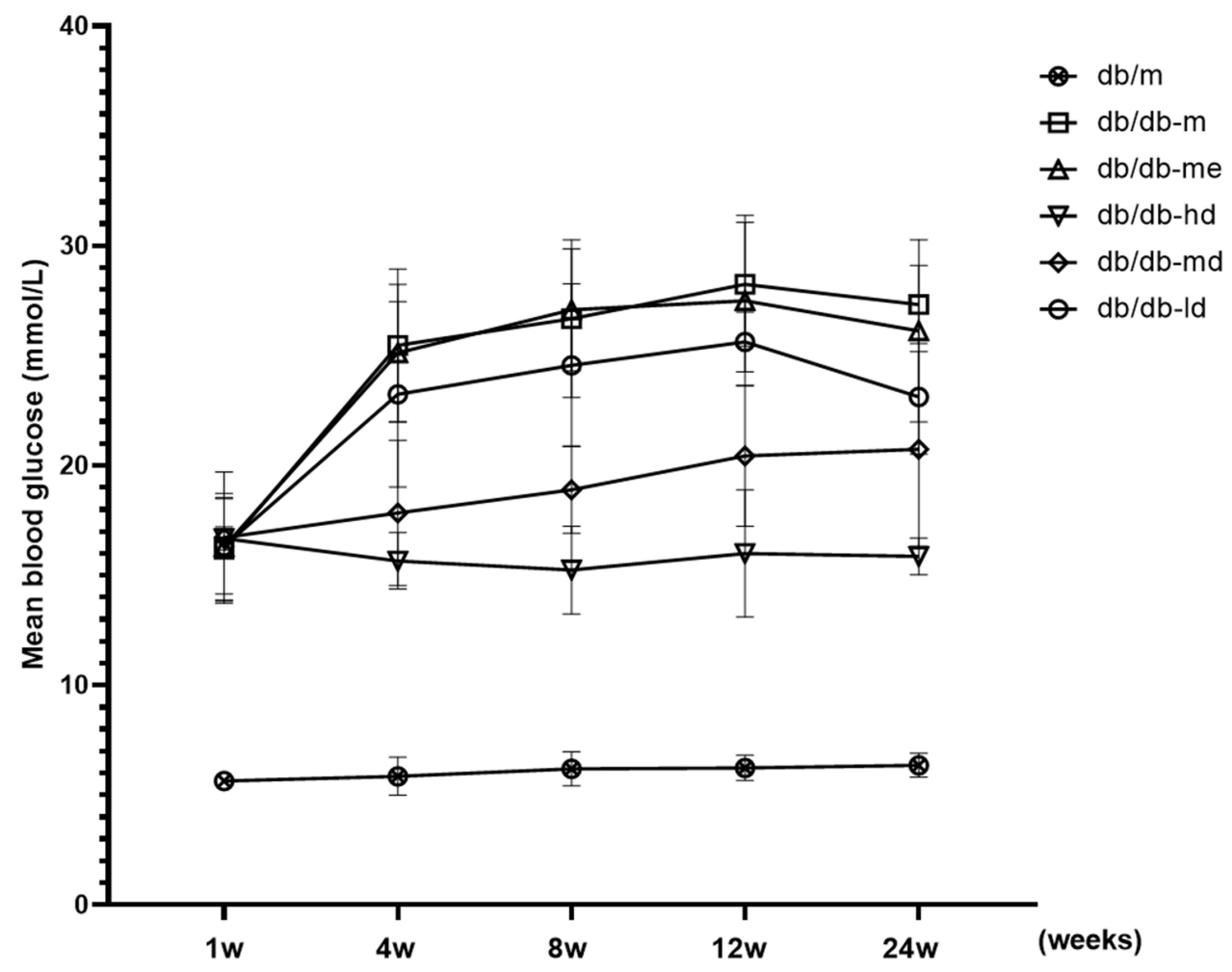

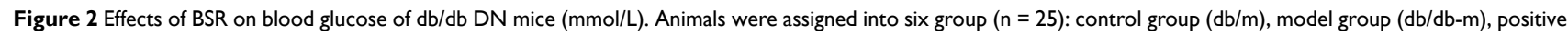
group (db/db-me) and BSR at high- (db/db-hd), medium- (db/db-md) and low (db/db-ld) doses group. The data are shown as the mean $\pm S D$. 


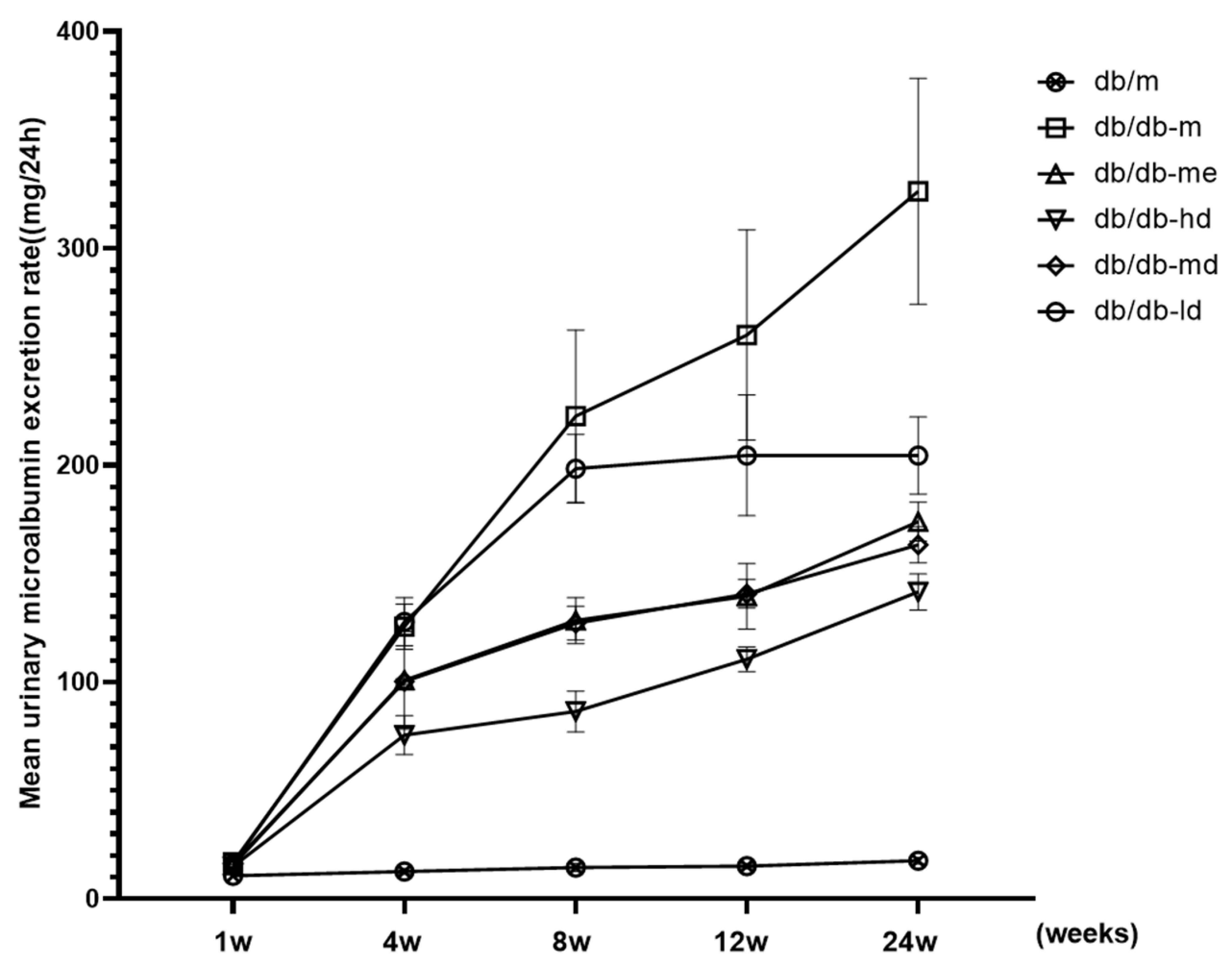

Figure 3 Effect of BSR on the UAER of db/db DN mice (mg/24-hours). Animals were assigned into six group $(n=25)$ : control group (db/m), model group (db/db-m), positive group (db/db-me) and BSR at high- (db/db-hd), medium- (db/db-md) and low (db/db-ld) doses group. The data are shown as the mean \pm SD.

\section{Effects of BSR on the Level of Blood Urea Nitrogen and Serum Creatinine in $\mathrm{db} / \mathrm{db}$ Mice}

The blood urea nitrogen (Figure 4) and serum creatinine (Figure 5) level of the $\mathrm{db} / \mathrm{m}$ group did not change significantly $(\mathrm{P}>0.05)$ in the feeding process, while a significant elevation could be observed in the db/db-m group at 12 weeks of feeding $(\mathrm{P}<0.01)$. Treating with positive drug and three doses of BSR could remarkably improve ( $\mathrm{P}<0.01$ for all) the elevated levels of both blood urea nitrogen and serum creatinine in $\mathrm{db} / \mathrm{db}$ mouse. Of note, animals in the $\mathrm{db} / \mathrm{db}-\mathrm{hd}$ group and the $\mathrm{db} / \mathrm{db}$-md group showed lower levels of both indicators as compared with that of in $\mathrm{db} / \mathrm{db}$-me group ( $\mathrm{P}<$ 0.01 for all), suggesting the pronounced improving renal function effects of both high- and medium doses of BSR.

\section{Effects of BSR on Histopathological Damage of DN in $\mathrm{db} / \mathrm{db}$ Mice}

H\&E staining was used to analyze the renal histopathological changes of $\mathrm{db} / \mathrm{db}$ mice before and after intervention with BSR. In the normal control group, the morphology and structure of the renal tissue were normal. Renal histopathological damages including proliferation of glomerular mesangial cells, dilation of the mesangial matrix, thickening of the capillary basement membrane, stenosis of partial capillaries, vacuolar degeneration of the epithelial cells of renal tubules, focal tubular atrophy, and interstitial fibrosis in $\mathrm{db} / \mathrm{db}$ mouse with DN could be improved at different degree by intervention with positive drug and three doses of BSR. Especially, in animals in $\mathrm{db} / \mathrm{db}$-hd group, a series of improvements such as basically normal glomerular volume, unobstructed lumen of most of the capillaries, intact renal tubular epithelium and mild degree of interstitial fibrosis could be observed (Figure 6).

Additionally, PAS staining was performed by blind method to quantify mesangial dilatation, and twenty glomeruli were observed. The degree of mesangial dilatation was scored from 0 to 3 , where 0 represented no mesangial dilatation, and 3 represented severe mesangial dilatation. The results revealed that the renal tissues of $\mathrm{db} / \mathrm{db}$-md group and $\mathrm{db} / \mathrm{db}$-hd group were significantly better than that of $\mathrm{db} / \mathrm{db}$-me group in improving renal histopathological damage (Table 1). 


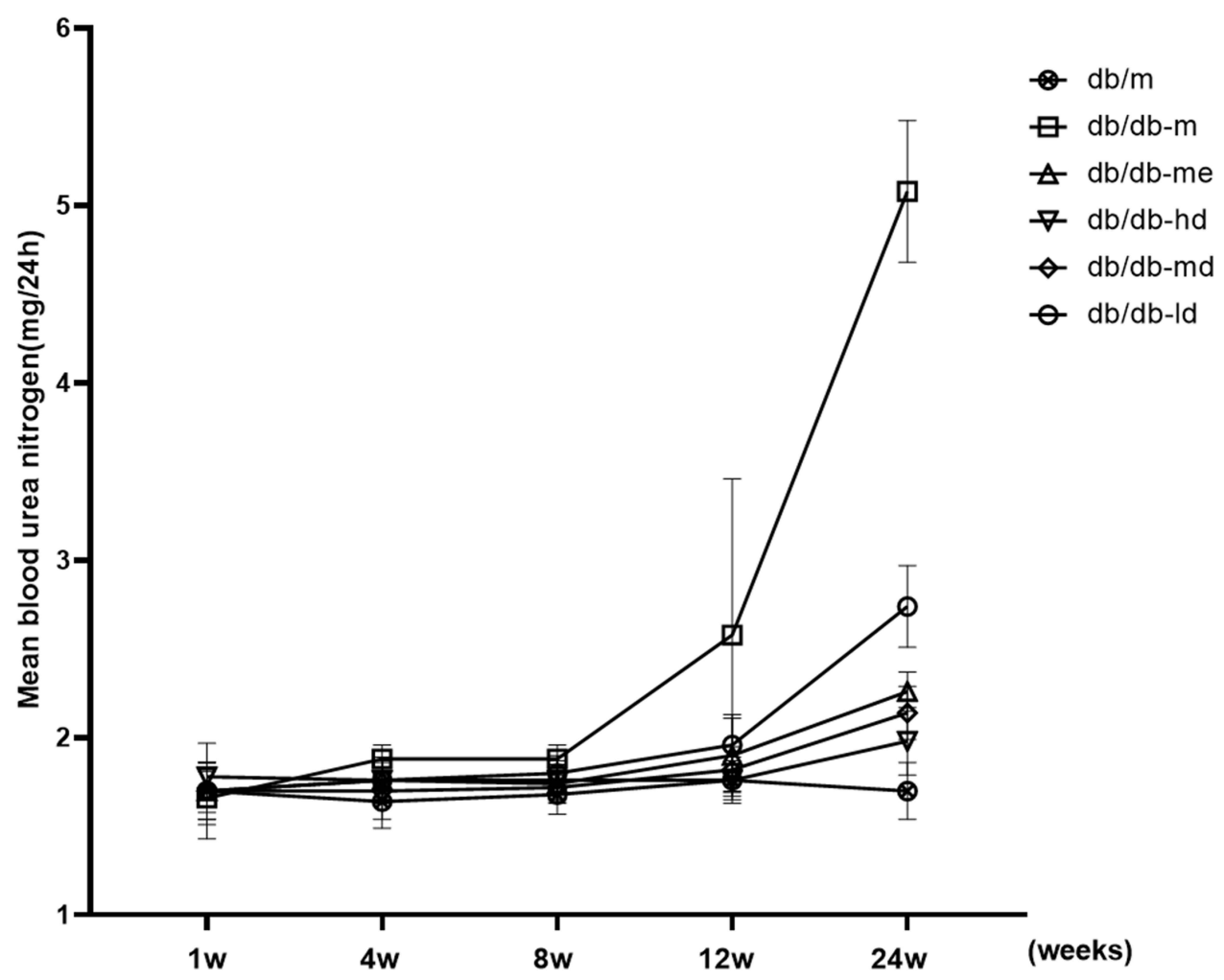

Figure 4 Effect of BSR on blood urea nitrogen level of $\mathrm{db} / \mathrm{db} \mathrm{DN}$ mice $(\mathrm{mg} / 24$-hours). Animals were assigned into six group $(\mathrm{n}=25)$ : control group $(\mathrm{db} / \mathrm{m})$, model group $(\mathrm{db} / \mathrm{db}-\mathrm{m})$, positive group (db/db-me) and BSR at high- (db/db-hd), medium- (db/db-md) and low (db/db-ld) doses group. The data are shown as the mean \pm SD.

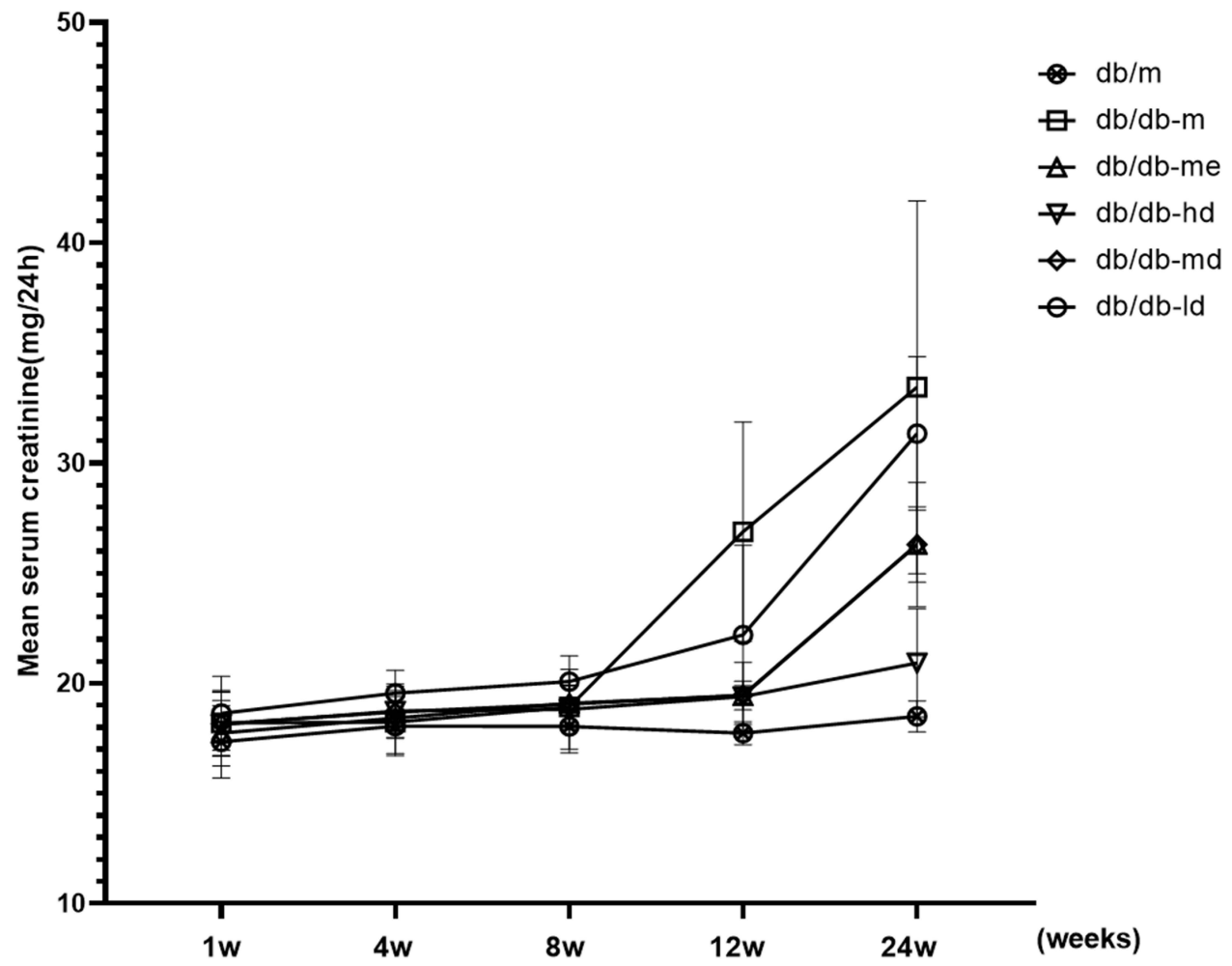

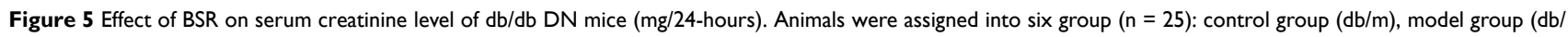
$\mathrm{db}-\mathrm{m})$, positive group (db/db-me) and BSR at high- (db/db-hd), medium- (db/db-md) and low (db/db-ld) doses group. The data are shown as the mean \pm SD. 


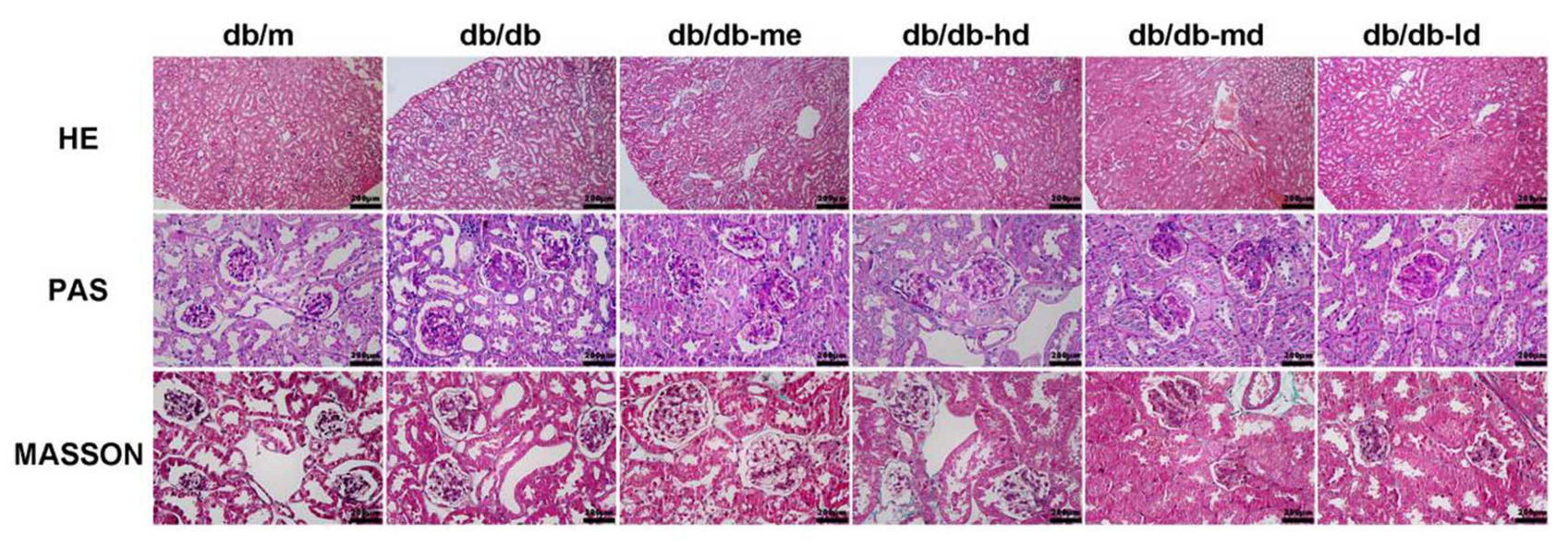

Figure 6 Pathological changes of DN in $\mathrm{db} / \mathrm{db}$ mice treated with BSR for 24 weeks. Animals were assigned into six group ( $n=25)$ : control group ( $d b / m)$, model group ( $d b /$ $\mathrm{db}-\mathrm{m})$, positive group (db/db-me) and BSR at high- (db/db-hd), medium- (db/db-md) and low (db/db-ld) doses group. The data are shown as the mean \pm SD.

\section{Effects of BSR on TNF- $\alpha$, IL-6, TNF-IR, and TNF-2R in Renal Tissue Homogenate of $\mathrm{db} / \mathrm{db}$ Mice}

In this study, IL-6, TNF- $\alpha$, TNF-1R, and TNF-2R in renal homogenate were detected by ELISA to further demonstrate the protective effect of BSR on DN. The results revealed that in the $\mathrm{db} / \mathrm{m}$ group, the levels of IL-6, TNF$\alpha, T N F-1 R$, and TNF-2R in renal homogenate did not significantly change with the extension of the experiment time $(\mathrm{P}<0.05)$. However, the levels of above-mentioned indicators of animals in $\mathrm{db} / \mathrm{db}$-m group exhibited significant elevation as compared with those in the control group at 8th, 12th, 16th, 20th, and 32nd weeks of feeding (corresponding to those at $0,4,8,12$, and 24 weeks of medication in the treatment group) ( $\mathrm{P}<0.01$ for all). It is noteworthy that intervention with high- $(\mathrm{P}<0.01)$, medium- $(\mathrm{P}<0.05)$ and low $(\mathrm{P}<0.05)$ doses of BSR could significantly reduce the levels of IL- 6 , TNF- $\alpha$, TNF$1 \mathrm{R}$, and TNF-2R, with high dose BSR having the best effect. Additionally, the levels of IL-6, TNF- $\alpha$, TNF-1R, and TNF-2R in renal homogenate in the $\mathrm{db} / \mathrm{db}$-md group were similar to $\mathrm{db} / \mathrm{db}$-me group $(\mathrm{P}>0.05)$. These results revealed that medium and high doses of BSR could significantly down-regulate the levels of IL-6, TNF-1R, and TNF-2R in renal tissue (Figure 7, Tables 2-5).

\section{Discussion}

With the clinical application of angiotensin-converting enzyme inhibitor (ACEI) and/or an angiotensin II receptor blocker (ARB), great changes have taken place in the treatment of diabetic nephropathy. However, the clinical application of ACEI and/or ARB has failed to reduce the incidence of ESRD in patients with diabetic nephropathy.

What is of great interest is that traditional Chinese herbal medicines with a long history of applications are widely used treatment for chronic kidney disease (CKD) in China and other Asian regions. They show good potential in improving clinical symptoms, controlling CKD proteinuria, and improving renal function. Additionally, the definite efficacies of Chinese herbal medicines on various renal diseases have been further confirmed via randomized case-control trials ${ }^{14-16}$ in recent years, which provided a beneficial strategy for treatment of various renal diseases such as DN.

In this study, BSR was obtained by compatibility of Astragalus, saffron, and rhubarb in a certain ratio. According to the theories of traditional Chinese medicine (TCM), the deficiency of spleen and kidney is the key to the development of DN, which determines the development and prognosis of this disease. Blood stasis, present throughout the course of diabetes, is not only the pathological product of diabetes, but also further

Table I Effect of BSR on Mesangial Matrix Dilation Score of db/db DN Mice (After 24 Weeks of Treatment)

\begin{tabular}{|l|l|l|l|l|l|l|l|}
\hline Group & $\mathbf{N}$ & $\mathbf{D b} / \mathbf{m}$ & $\mathbf{d b} / \mathbf{d b}-\mathbf{m}$ & $\mathbf{d b} / \mathbf{d b}-\mathbf{m e}$ & $\mathbf{d b} / \mathbf{d b}-\mathbf{h d}$ & $\mathbf{d b} / \mathbf{d b}-\mathbf{m d}$ & $\mathbf{d b} / \mathbf{d b}-\mathbf{l d}$ \\
\hline Score of mesangial dilatation & 6 & - & $2.60 \pm 0.40^{\#}$ & $0.95 \pm 0.51^{*}$ & $0.75 \pm 0.51^{* \#}$ & $0.87 \pm 0.8^{* \#}$ & $1.00 \pm 0.72^{*}$ \\
\hline
\end{tabular}

Notes: db/m: blank control group, db/db-m: model group, db/db-me: positive control group, db/db-hd: high-dose treatment group, db/db-md: medium-dose treatment group, db/db-ld: low-dose treatment group. Compared with $\mathrm{db} / \mathrm{db}-\mathrm{m}$ group, $* \mathrm{p}<0.0 \mathrm{l}$; compared with $\mathrm{db} / \mathrm{db}-\mathrm{me}$ group, ${ }^{\#} \mathrm{p}<0.0 \mathrm{I}$. 

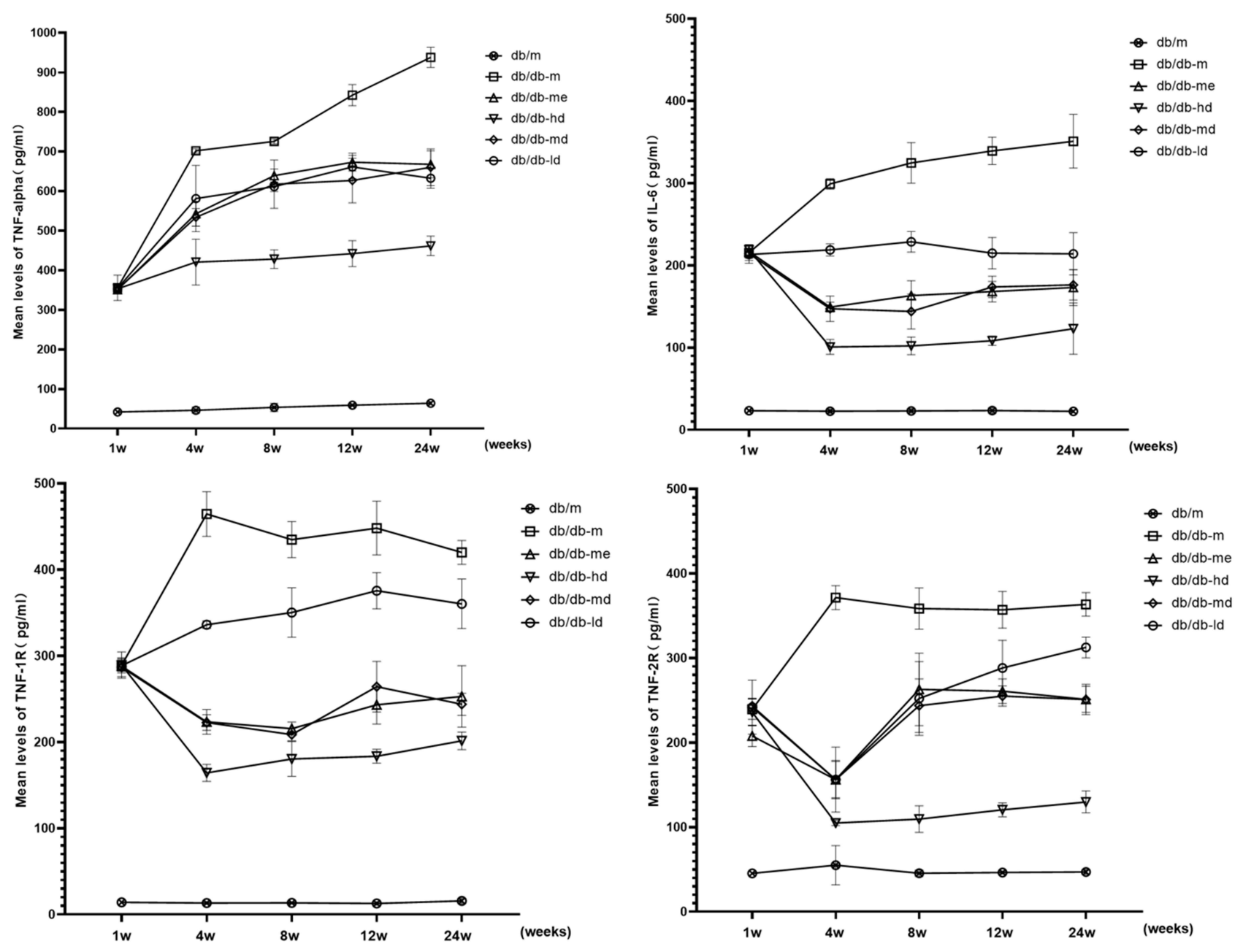

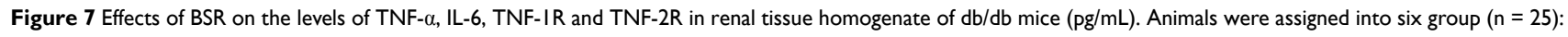
control group (db/m), model group (db/db-m), positive group (db/db-me) and BSR at high- (db/db-hd), medium- (db/db-md) and low (db/db-ld) doses group. The data are shown as the mean \pm SD.

lead to the occurrence of diabetes, which is also the main cause of various complications such as $\mathrm{DN}$ of diabetes. The compatibility of the three Chinese herbal medicines perform the effects of invigorating qi and strengthening spleen, activating blood circulation, and removing blood stasis, dampness, and turbidity, which is consistent with the pathogenesis of DN. Additionally, applying BSR on DN is also in accordance with the basic principles of TCM on the syndrome differentiation and treatment of DN.

Table 2 Effects of BSR on the Levels of IL-6 in Renal Tissue Homogenate of $\mathrm{db} / \mathrm{db}$ Mice $(\mathrm{pg} / \mathrm{mL})$

\begin{tabular}{|l|l|l|l|l|l|}
\hline \multirow{2}{*}{ Group } & \multicolumn{5}{|c|}{ Time (Weeks) } \\
\cline { 2 - 6 } & \multicolumn{1}{|c|}{$\mathbf{0}$} & \multicolumn{1}{|c|}{$\mathbf{4}$} & \multicolumn{1}{|c|}{$\mathbf{8}$} & \multicolumn{1}{c|}{24} \\
\hline $\mathrm{db} / \mathrm{m}$ & $23.44 \pm 3.88^{* \#}$ & $22.80 \pm 2.77^{* \#}$ & $23.16 \pm 2.74^{* \#}$ & $23.57 \pm 3.48^{* \#}$ & $22.54 \pm 1.74^{* \#}$ \\
$\mathrm{db} / \mathrm{db}-\mathrm{m}$ & $215.54 \pm 9.44$ & $299.15 \pm 6.33^{\#}$ & $324.64 \pm 24.59^{\#}$ & $339.35 \pm 16.60^{\#}$ & $351.01 \pm 32.65^{\#}$ \\
$\mathrm{db} / \mathrm{db}-\mathrm{hd}$ & $219.00 \pm 5.97$ & $100.87 \pm 9.09^{* \#}$ & $102.18 \pm 10.72^{* \#}$ & $108.38 \pm 5.57^{* \#}$ & $123.12 \pm 31.14^{* \#}$ \\
$\mathrm{db} / \mathrm{db}-\mathrm{md}$ & $214.28 \pm 4.00$ & $147.34 \pm 15.35^{*}$ & $144.13 \pm 21.20^{* \#}$ & $173.81 \pm 12.98^{*}$ & $176.39 \pm 18.42^{*}$ \\
$\mathrm{db} / \mathrm{db}-\mathrm{ld}$ & $213.32 \pm 10.71$ & $218.93 \pm 7.36^{* \#}$ & $228.74 \pm 12.56^{* \#}$ & $214.92 \pm 19.16^{* \#}$ & $214.17 \pm 25.63^{* \#}$ \\
$\mathrm{db} / \mathrm{db}-\mathrm{me}$ & $216.91 \pm 8.26$ & $149.40 \pm 5.93^{*}$ & $163.29 \pm 18.14^{*}$ & $168.21 \pm 12.38^{*}$ & $173.16 \pm 21.75^{*}$ \\
\hline
\end{tabular}

Notes: IL-6 level were detected using Mouse IL-6 ELISA kit. Results were shown as the mean \pm SD. Compared with db/db-m group, *P $<0.01$; compared with $\mathrm{db} / \mathrm{db}-\mathrm{me}$ group, ${ }_{\mathrm{p}}<0.01$. 
Table 3 Effects of BSR on the Levels of TNF- $\alpha$ in Renal Tissue Homogenate of $\mathrm{db} / \mathrm{db}$ Mice (pg/mL)

\begin{tabular}{|l|l|l|l|l|l|}
\hline \multirow{2}{*}{ Group } & \multicolumn{5}{|c|}{ Time (Weeks) } \\
\cline { 2 - 6 } & \multicolumn{1}{|c|}{$\mathbf{0}$} & \multicolumn{1}{|c|}{$\mathbf{4}$} & \multicolumn{1}{|c|}{$\mathbf{8}$} & \multicolumn{1}{|c|}{$\mathbf{2 4}$} \\
\hline $\mathrm{db} / \mathrm{m}$ & $42.31 \pm 7.94^{* \#}$ & $46.51 \pm 8.3 \mathrm{I}^{* \#}$ & $53.70 \pm 10.33^{* \#}$ & $59.47 \pm 3.27^{* \#}$ & $64.35 \pm 4.25^{* \#}$ \\
$\mathrm{db} / \mathrm{db}-\mathrm{m}$ & $355.87 \pm 31.99$ & $701.96 \pm 4.83^{\#}$ & $725.52 \pm 5.80^{\#}$ & $842.29 \pm 26.73^{\#}$ & $937.83 \pm 25.44^{\#}$ \\
$\mathrm{db} / \mathrm{db}-\mathrm{hd}$ & $353.43 \pm 9.40$ & $420.79 \pm 57.92^{* \#}$ & $428.16 \pm 23.36^{* \#}$ & $442.18 \pm 32.50^{* \#}$ & $461.63 \pm 24.50^{* \#}$ \\
$\mathrm{db} / \mathrm{db}-\mathrm{md}$ & $352.47 \pm 5.61$ & $533.77 \pm 22.24^{*}$ & $617.51 \pm 60.92^{*}$ & $626.77 \pm 56.53^{* \#}$ & $660.14 \pm 46.42^{*}$ \\
$\mathrm{db} / \mathrm{db}-\mathrm{ld}$ & $354.63 \pm 4.52$ & $581.36 \pm 83.8 \mathrm{I}^{* \#}$ & $611.33 \pm 12.13^{* \#}$ & $661.11 \pm 29.43^{*}$ & $632.56 \pm 24.97^{* \#}$ \\
$\mathrm{db} / \mathrm{db}-\mathrm{me}$ & $350.89 \pm 7.80$ & $542.90 \pm 31.46^{*}$ & $639.11 \pm 16.33^{*}$ & $673.09 \pm 22.56^{*}$ & $667.66 \pm 34.16^{*}$ \\
\hline
\end{tabular}

Notes: TNF- $\alpha$ level were detected using Mouse TNF- $\alpha$ ELISA kit. Results were shown as the mean $\pm S D$. Compared with db/db-m group, ${ }^{P} P<0.01 ;$ compared with db/db-me group, ${ }_{\mathrm{p}}<0.01$.

Table 4 Effects of BSR on the Levels of TNF-IR in Renal Tissue Homogenate of $\mathrm{db} / \mathrm{db}$ Mice $(\mathrm{pg} / \mathrm{mL})$

\begin{tabular}{|l|l|l|l|l|l|}
\hline \multirow{2}{*}{ Group } & \multicolumn{5}{|c|}{ Time (Weeks) } \\
\cline { 2 - 6 } & \multicolumn{1}{|c|}{$\mathbf{0}$} & \multicolumn{1}{|c|}{$\mathbf{4}$} & \multicolumn{1}{|c|}{$\mathbf{8}$} & \multicolumn{1}{|c|}{12} & \multicolumn{1}{|c|}{24} \\
\hline $\mathrm{db} / \mathrm{m}$ & $14.18 \pm 2.35^{* \#}$ & $13.40 \pm 1.86^{* \#}$ & $13.61 \pm 1.00^{* \#}$ & $12.87 \pm 2.03^{* \#}$ & $15.80 \pm 3.05^{* \#}$ \\
$\mathrm{db} / \mathrm{db}-\mathrm{m}$ & $289.06 \pm 6.65$ & $464.49 \pm 25.95^{\#}$ & $434.83 \pm 20.97^{\#}$ & $448.20 \pm 31.14^{\#}$ & $420.00 \pm 13.87^{\#}$ \\
$\mathrm{db} / \mathrm{db}-\mathrm{hd}$ & $289.37 \pm 15.25$ & $164.28 \pm 9.88^{* \#}$ & $180.52 \pm 20.18^{* \#}$ & $183.55 \pm 8.10^{* \#}$ & $201.50 \pm 10.14^{* \#}$ \\
$\mathrm{db} / \mathrm{db}-\mathrm{md}$ & $286.84 \pm 10.92$ & $222.77 \pm 8.9 I^{*}$ & $208.70 \pm 7.05^{*}$ & $264.30 \pm 29.30^{* \#}$ & $243.90 \pm 12.74^{*}$ \\
$\mathrm{db} / \mathrm{db}-\mathrm{ld}$ & $288.69 \pm 8.35$ & $336.20 \pm 4.56^{* \#}$ & $350.28 \pm 28.63^{* \#}$ & $375.57 \pm 20.95^{* \#}$ & $360.40 \pm 28.67^{* \#}$ \\
$\mathrm{db} / \mathrm{db}-\mathrm{me}$ & $288.20 \pm 6.15$ & $223.51 \pm 14.32^{*}$ & $215.66 \pm 7.60^{*}$ & $243.34 \pm 22.24^{*}$ & $252.98 \pm 35.60^{*}$ \\
\hline
\end{tabular}

Notes: TNF-IR level were detected using Mouse TNF-IR ELISA kit. Results were shown as the mean \pm SD. Compared with db/db-m group, *P $<0.01 ;$ compared with db/dbme group, ${ }_{\mathrm{P}}<0.01$.

Table 5 Effects of BSR on the Levels of TNF-2R in Renal Tissue Homogenate of $\mathrm{db} / \mathrm{db}$ Mice $(\mathrm{pg} / \mathrm{mL})$

\begin{tabular}{|c|c|c|c|c|c|}
\hline \multirow[t]{2}{*}{ Group } & \multicolumn{5}{|c|}{ Time (Weeks) } \\
\hline & 0 & 4 & 8 & 12 & 24 \\
\hline $\mathrm{db} / \mathrm{m}$ & $45.42 \pm 3.32 * \#$ & $55.11 \pm 23.22^{* \#}$ & $45.61 \pm 3.87^{* \#}$ & $46.44 \pm 1.80 * \#$ & $47.18 \pm 2.82 * \#$ \\
\hline $\mathrm{db} / \mathrm{db}-\mathrm{m}$ & $239.5 I \pm 12.04$ & $371.50 \pm 14.08^{\#}$ & $358.50 \pm 24.33^{\#}$ & $357.04 \pm 21.72^{\#}$ & $363.49 \pm|3.9|^{\#}$ \\
\hline $\mathrm{db} / \mathrm{db}-\mathrm{hd}$ & $236.06 \pm 16.20$ & $104.93 \pm 3.05 * \#$ & $109.59 \pm 15.57^{* \#}$ & $120.64 \pm 8.23 * \#$ & $129.89 \pm 12.88$ \\
\hline $\mathrm{db} / \mathrm{db}-\mathrm{md}$ & $243.28 \pm 9.01$ & $156.29 \pm 22.62 *$ & $243.69 \pm 31.71$ *\# & $255.10 \pm 12.06 *$ & $250.96 \pm 17.87^{*}$ \\
\hline $\mathrm{db} / \mathrm{db}-\mathrm{ld}$ & $241.97 \pm 31.92$ & $223.89 \pm 38.52^{* \#}$ & $252.35 \pm 43.55 *$ & $288.31 \pm 32.65^{* \#}$ & $312.59 \pm 12.26$ *\# \\
\hline $\mathrm{db} / \mathrm{db}-\mathrm{me}$ & $207.96 \pm 12.66$ & $160.11 \pm 21.39 *$ & $262.92 \pm 42.88^{*}$ & $260.82 \pm 14.44^{*}$ & $25|.2| \pm \mid 5.50 *$ \\
\hline
\end{tabular}

Notes: TNF-2R level were detected using Mouse TNF-2R ELISA kit. Results were shown as the mean \pm SD. Compared with db/db-m group, *P $<0.01 ;$ compared with db/dbme group, ${ }^{\#}<0.01$.

ACEIs and receptor antagonists are commonly used in the treatment of proteinuria. A study reported that in adults, ACEI or ARB could reduce proteinuria by $30-50 \%$. Current guidelines also recommend these for the diagnosis and treatment of DB. ${ }^{17-19}$ Therefore, in this study, irbesartan was used as a positive control to evaluate the clinical effect of BSR. This study revealed that the blood glucose level of $\mathrm{db} / \mathrm{db}$ mice began to increase at the 8th week, but the UAER did not increase significantly. Renal histology revealed that there were no significant changes in mesangial cells and matrix. In the 12th week, the UAER was increased. In addition, renal pathological results also reveal an increase of mesangial cells and dilation of the matrix. These indicated the formation of DN. This is consistent with the early changes of $\mathrm{DN}$ in $\mathrm{db} / \mathrm{db}$ mice reported by Simonson ${ }^{20}$ at the age of $8-16$ weeks. In this study, db/db mice models of DN were treated with low, medium, and high doses of BSR, and the ARB drug irbesartan was used as a positive control. The mice were observed for 24 weeks. The results revealed that the body weight, blood glucose, UAER, blood urea nitrogen, and creatinine levels of $\mathrm{db} / \mathrm{db}$ mice were significantly decreased in the $\mathrm{db} / \mathrm{db}$-ld group, the $\mathrm{db} / \mathrm{db}$-md group, and the $\mathrm{db} / \mathrm{db}$-hd group. Compared with the 
$\mathrm{db} / \mathrm{db}$-me group, the $\mathrm{db} / \mathrm{db}$-hd group and the $\mathrm{db} / \mathrm{db}$-md group had obvious advantages in controlling body weight, blood glucose, UAER, blood urea nitrogen, and creatinine levels. Renal pathological results at the same time points also revealed that the $\mathrm{db} / \mathrm{db}$-md group and $\mathrm{db} / \mathrm{db}$-hd group had significant advantages in the reduction of mesangial matrix proliferation and the degree of interstitial fibrosis. These results indicate that BSR can improve DN, control proteinuria, and improve renal function, and is better than ARB drugs in controlling blood glucose and reducing body weight.

Modern TCM studies revealed that astragalus in the prescription could improve cisplatin-induced acute kidney injury $(\mathrm{AKI})^{21}$ and enhance LPS-induced NO production in macrophages of patients with renal failure. ${ }^{22}$ Astragalus polysaccharide, an active component of astragalus, can significantly improve the renal pathology and renal fibrosis index of streptozotocin-induced $\mathrm{DN}^{23}$ Rhubarb in the prescription has a variety of active components. ${ }^{24}$ One of these components, emodin, can reduce 24-hour proteinuria and improve renal pathology in diabetic rats, inhibit the p38 mitogen-activated protein kinase (MAPK) pathway, decrease the expression of fibronectin in renal tissue of DN rats, and improve the proliferation of glomerular basement membrane. It can prevent the synthesis of extracellular matrix and down-regulated expressions of TNF- $\alpha$, IL-6, and Toll-like receptor 4 in renal tissue. $^{25-27}$ Another component, rhein, can down-regulate the expression of oxidative stress products, relieve inflammation in the kidney, reduce the synthesis of TXB2, and improve renal hemodynamics through anticoagulation, playing a role in renal protection. ${ }^{24}$ Rhein can reduce the expression of TNF- $\alpha$ and IL-1 $\beta$ in renal tissue of sepsis rats, inhibit NF-kB pathway activity, ${ }^{28}$ prevent and treat $\mathrm{AKI}$, and reduce the levels of TGF- $\beta$ and $\alpha$-smooth muscle actin in renal tissue of rats with obstructive nephropathy and DN. ${ }^{29,30}$ Chrysophanol can improve renal interstitial fibrosis by inhibiting the TGF- $\beta$ / Smad signaling pathway, reducing the formation of reactive oxygen-free radicals. ${ }^{31}$ Saffron in the prescription has antiinflammatory, antioxidant, and insulin-sensitizing effects. ${ }^{32}$ Milajerdi et $\mathrm{al}^{33}$ conducted a randomized, three-blinded, controlled study on 54 patients with T2DM. The result revealed that saffron could down-regulate blood glucose and HbA1c. It has been found that saffron extract contains a variety of active components. Among these, $\beta$-carotene, with its many biological properties, can reduce the apoptosis of islet $\beta$ cells by eliminating free radicals, inhibiting oxidative stress, and inhibiting the expression of $\mathrm{p} 53$, protecting islet beta cells and improving islet function. Saffron extracts can also inhibit the plasma creatinine concentration, malondialdehyde level, TNF- $\alpha$, ICAM-1 expression, and leukocyte infiltration of ischemiareperfusion AKI models. ${ }^{34,35}$ Based on the above studies, $\mathrm{BSR}$, the prescription in this study, may play a renal protective role in DN by improving islet function, lowering blood glucose levels, inhibiting oxidative stress, improving blood coagulation, and inhibiting inflammation and fibrosis.

Activation of the innate immune system and chronic lowgrade inflammation are important components of the pathogenesis of T2DM. Improving oxidative stress is one of the main therapeutic targets of DN. The serum level of IL-6 in patients with DN is significantly increased and significantly correlated with albuminuria excretion and glomerular basement membrane thickening. ${ }^{36} \mathrm{TNF}-\alpha$ is a pleiotropic cytokine that can activate a variety of downstream molecules related to vascular endothelial dysfunction, such as ICAM-1, VCAM-1, PAI-1, and systemic inflammatory markers such as IL-6 and C-reactive protein. The level of circulating markers of the TNF pathway is closely related to the risk of UAER, impaired renal function, and cardiovascular death. ${ }^{37,38}$ A cohort study conducted observations for 8-12 years of 410 patients with T2DM. The result revealed that 59 patients developed ESRF and the baseline TNF-1R and TNF-2R levels were closely related to the risk of ESRF. ${ }^{39}$ In this study, IL- $6, \mathrm{TNF}-\alpha$, TNF1R, and TNF2R in renal tissue homogenate of $\mathrm{db} / \mathrm{db} \mathrm{DN}$ model mice were detected by ELISA to further clarify the antiinflammatory effect in the treatment of DN. The levels of these factors in renal tissue homogenate were monitored in this study. The results revealed that at 12 weeks of age, TNF1R, TNF2R, and IL-6 in renal tissue homogenate of $\mathrm{db} / \mathrm{db}$ mice in the $\mathrm{db} / \mathrm{db}$-m group were increased significantly. After the mice were treated with BSR, the levels of IL-6, TNF1R, and TNF2R in renal tissue were significantly decreased, and the corresponding pathological findings of renal tissue revealed that the proliferation of mesangial cells and matrix decreased. These results indicate that BSR may delay the progression of DN by inhibiting inflammation.

Although our data showed that BSR could delay the pathology and reduce the expression of inflammatory in mice with $\mathrm{DN}$, in-depth mechanisms such as the potential signal pathway, target and molecular mechanism of BSR on protection the renal damage induced by DN still need to be further explored.

\section{Conclusion}

In summary, BSR, a traditional Chinese medicine prescription, could effectively delay the pathological damage induced by $\mathrm{DN}$, mainly manifested as reducing the levels of a series of indicators including blood glucose, body weight, urinary albumin, blood urea nitrogen, creatinine and improving renal 
pathology. Additionally, the down-regulation effects of BSR on renal levels of IL-6, TNF- $\alpha$, TNF-1R, and TNF-2R indicated that BSR may perform nephroprotective effects partly through anti-inflammation mechanism. This study not only demonstrates the protective effect of BSR on DN from the perspective of anti-inflammation, but also provides a theoretical basis for the development of traditional Chinese medicine herb drug therapy for $\mathrm{DN}$.

\section{Ethical Approval}

All applicable international, national, and/or institutional guidelines for the care and use of animals were followed. This study was conducted with approval from the Ethics Committee of Lanzhou University Second Hospital.

\section{Acknowledgments}

We would like to acknowledge the hard and dedicated work of all the staff that implemented the intervention and evaluation components of the study.

\section{Funding}

Lanzhou Science and Technology Bureau talent innovation project (2014-RC-64).

\section{Disclosure}

The authors declare that they have no competing interests.

\section{References}

1. Ansell D, Feehally J, Feest TG, et al. UK Renal Registry Report. Bristol, UK: UK Renal Registry; 2008:49-74.

2. Remuzzi G, Schieppati A, Ruggenenti P. Clinical practice. Nephropathy in patients with type 2 diabetes. $N$ Engl $J$ Med. 2002;346(15):1145-1151. doi:10.1056/NEJMcp011773

3. Shaw JE, Sicree RA, Zimmet PZ. Global estimates of the prevalence of diabetes for 2010 and 2030. Diabetes Res Clin Pract. 2010;87 (1):4-14. doi:10.1016/j.diabres.2009.10.007

4. Altemtam N, Russe J, El Nahas M. A study of the natural history of diabetic kidney disease (DKD). Nephrol Dial Transplant. 2012;27 (5):1847-1854. doi:10.1093/ndt/gfr561

5. Domingueti CP, Dusse LMS, Carvalho MG, et al. Diabetes mellitus: the linkage between oxidative stress, inflammation, hypercoagulability and vascular complications. J Diabetes Complications. 2016;30 (4):738-7454. doi:10.1016/j.jdiacomp.2015.12.018

6. Yaribeygi H, Atkin SL, Sahebkar A. A review of the molecular mechanisms of hyperglycemia-induced free radical generation leading to oxidative stress. J Cell Physiol. 2018;234(2):1300-1312.

7. Song P, Sun C, Jinbo L, et al. Tiliacora triandra extract and its major constituent attenuates diabetic kidney and testicular impairment by modulating redox imbalance and pro-inflammatory responses in rats. J Sci Food Agric. 2021;101(4):1598-1608. doi:10.1002/jsfa.10779

8. Ziyuan N, Guo L, Liu F, et al. Allium tuberosum alleviates diabetic nephropathy by suppressing hyperglycemia-induced oxidative stress and inflammation in high fat diet/streptozotocin treated rats. Biomed Pharmacother. 2019;112:108678. doi:10.1016/j.biopha.2019.108678
9. Olatunji OJ, Chen H, Zhou Y. Lycium chinense leaves extract ameliorates diabetic nephropathy by suppressing hyperglycemia mediated renal oxidative stress and inflammation. Biomed Pharmacother. 2018;102:1145-1151. doi:10.1016/j.biopha.2018.03.037

10. Chen Y, Deng Y, Ni Z, et al. Efficacy and safety of traditional Chinese medicine (Shenqi particle) for patients with idiopathic membranous nephropathy: a multicenter randomized controlled clinical trial. Am J Kidney Dis. 2013;62(6):1068-1076. doi:10.1053/j.ajkd.2013.05.005

11. Zou C, Lu ZY, Wu YC, et al. Colon may provide new therapeutic targets for treatment of chronic kidney disease with Chinese medicine. Chin J Integr Med. 2013;19(2):86-91. doi:10.1007/ s11655-013-1351-8

12. Huang KC, Su YC, Sun MF, et al. Chinese herbal medicine improves the long-term survival rate of patients with chronic kidney disease in Taiwan: a nationwide retrospective population-based cohort study. Front Pharmacol. 2018;9:1117. doi:10.3389/fphar.2018.01117

13. Liu W, Wang J, Wang X, et al. Effects of shenbao recipe on expressions of CTGF and MMP-9 in diabetic nephropathy rats. Zhongguo Zhong Yao Za Zhi. 2010;35(14):1874-1877.

14. Zhang Z, Zhang L, Hansong X. Effect of Astragalus polysaccharide in treatment of diabetes mellitus: a narrative review. $J$ Tradit Chin Med. 2019;39(1):133-138.

15. Azimi P, Ghiasvand R, Feizi A, et al. Effects of cinnamon, cardamom, saffron, and ginger consumption on markers of glycemic control, lipid profile, oxidative stress, and inflammation in Type 2 diabetes patients. Rev Diabet Stud. 2014;11(3-4):258-266. doi:10.1900/RDS.2014.11.258

16. Régnier M, Rastelli M, Morissette A, et al. Rhubarb supplementation prevents diet-induced obesity and diabetes in association with increased Akkermansia muciniphila in mice. Nutrients. 2020;12 (10):2932. doi:10.3390/nu12102932

17. Lewis EJ, Hunsicker LG, Bain RP, et al.; The Collaborative Study Group. The effect of angiotensin-converting-enzyme inhibition on diabetic nephropathy. $N$ Engl J Med. 1993;329(20):1456-1462. doi:10.1056/NEJM199311113292004.

18. Brenner BM, Cooper ME, de Zeeuw D, et al. Effects of losartan on renal and cardiovascular outcomes in patients with type 2 diabetes and nephropathy. N Engl J Med. 2001;345(12):861-869. doi:10.1056/ NEJMoa011161

19. Doshi SM, Friedman AN. Diagnosis and management of Type 2 diabetic kidney disease. Clin J Am Soc Nephrol. 2017;12 (8):1366-1373. doi:10.2215/CJN.11111016

20. Simonson MS, Tiktin M, Debanne SM, et al. The renal transcriptome of $\mathrm{db} / \mathrm{db}$ mice identifies putative urinary biomarker proteins in patients with type 2 diabetes: a pilot study. Am J Physiol Renal Physiol. 2012;302(7):F820-9. doi:10.1152/ajprenal.00424.2011

21. Hui D, Rui-Zhi T, Jian-Chun L, et al. Astragalus propinquus Schischkin and Panax notoginseng (A\&P) compound relieved cisplatin-induced acute kidney injury through inhibiting the mincle maintained macrophage inflammation. $J$ Ethnopharmacol. 2020;252:112637. doi:10.1016/j.jep.2020.112637

22. Liao $\mathrm{H}, \mathrm{Hu} \mathrm{L}$, Cheng $\mathrm{XN}$, et al. Are the therapeutic effects of Huangqi (Astragalus membranaceus) on diabetic nephropathy correlated with its regulation of macrophage iNOS activity? J Immunol Res. 2017;2017:3780572.

23. wang ZS, Xiong F, Xie XH, et al. Astragaloside IV attenuates proteinuria in streptozotocin-induced diabetic nephropathy via the inhibition of endoplasmic reticulum stress. BMC Nephrol. 2015;16(1):44. doi:10.1186/s12882-015-0031-7

24. Cao YJ, Pu ZJ, Tang YP, et al. Advances in bio-active constituents, pharmacology and clinical applications of rhubarb. Chin Med. 2017;12(1):36. doi:10.1186/s13020-017-0158-5

25. Dou F, Liu YT, Liu LM, et al. Aloe-emodin ameliorates renal fibrosis via inhibiting PI3K/Akt/mTOR signaling pathway in vivo and in vitro. Rejuvenation Res. 2019;22(3):218-229. doi:10.1089/rej.201 8.2104 
26. Wang JP, Huang HQ, Liu PQ, et al. Inhibition of phosphorylation of p38 MAPK involved in the protection of nephropathy by emodin in diabetic rats. Eur J Pharmacol. 2006;553(1-3):297-303. doi:10.10 16/j.ejphar.2006.08.087

27. Zhu XL, Wang YJ, Yang YZ, et al. Suppression of lipopolysaccharide-induced upregulation of toll-like receptor 4 by emodin in mouse proximal tubular epithelial cells. Mol Med Rep. 2012;6(3):493-500. doi:10.3892/mmr.2012.960

28. Yu C, Qi D, Sun JF, et al. Rhein prevents endotoxin-induced acute

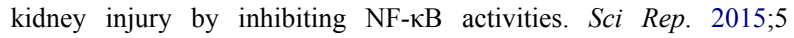
(1):11822. doi:10.1038/srep11822

29. He D, Lee L, Yang J, et al. Preventive effects and mechanisms of rhein on renal interstitial fibrosis in obstructive nephropathy. Biol Pharm Bull. 2011;34(8):1219-1226. doi:10.1248/bpb.34.1219

30. Gao Q, Qin WS, Jia ZH, et al. Rhein improves renal lesion and ameliorates dyslipidemia in $\mathrm{db} / \mathrm{db}$ mice with diabetic nephropathy. Planta Med. 2010;76(1):27-33. doi:10.1055/s-0029-1185948

31. Dou F, Ding Y, Wang C, et al. Chrysophanol ameliorates renal interstitial fibrosis by inhibiting the TGF- $\beta /$ Smad signaling pathway. Biochem Pharmacol. 2020;180:114079. doi:10.1016/j.bcp.202 0.114079

32. Yaribeygi H, Zare V, Butler AE, et al. Antidiabetic potential of saffron and its active constituents. J Cell Physiol. 2019;4(6):8610-8 617. doi:10.1002/jcp. 27843
33. Milajerdi A, Jazayeri S, Hashemzadeh N, et al. The effect of saffron (Crocus sativus L.) hydroalcoholic extract on metabolic control in type 2 diabetes mellitus: a triple-blinded randomized clinical trial. J Res Med Sci. 2018;23(1):16. doi:10.4103/jrms.JRMS_286_17

34. Mahmoudzadeh L, Najafi H, Ashtiyani SC, et al. Anti-inflammatory and protective effects of saffron extract in ischaemia-reperfusion induced acute kidney injury. Nephrology. 2017;22(10):748-754. doi:10.1111/nep.12849

35. Rameshrad M, Razavi BM, Hosseinzadeh H. Saffron and its derivatives, crocin, crocetin and safranal: a patent review. Expert Opin Ther Pat. 2018;28(2):147-165. doi:10.1080/13543776.2017.1355909

36. Satirapoj B. Tubulointerstitial biomarkers for diabetic nephropathy. J Diabetes Res. 2018;2018:2852398. doi:10.1155/2018/2852398

37. Ernandez T, Mayadas TN. Immunoregulatory role of TNF-alpha in inflammatory kidney diseases. Kidney Int. 2009;76(3):262-276. doi:10.1038/ki.2009.142

38. Navarro JF, Mora-Fernández C. The role of TNF-alpha in diabetic nephropathy: pathogenic and therapeutic implications. Cytokine Growth Factor Rev. 2006;17(6):441-450. doi:10.1016/j.cytogfr.20 06.09.011

39. Niewczas MA, Gohda T, Skupien J, et al. Circulating TNF receptors 1 and 2 predict ESRD in Type 2 diabetes. J Am Soc Nephrol. 2012;23 (3):507-515. doi:10.1681/ASN.2011060627

\section{Publish your work in this journal}

Diabetes, Metabolic Syndrome and Obesity: Targets and Therapy is an international, peer-reviewed open-access journal committed to the rapid publication of the latest laboratory and clinical findings in the fields of diabetes, metabolic syndrome and obesity research. Original research, review, case reports, hypothesis formation, expert opinion and commentaries are all considered for publication. The manuscript management system is completely online and includes a very quick and fair peer-review system, which is all easy to use. Visit http://www.dovepress.com/testimonials.php to read real quotes from published authors. 